\title{
Nuptial food gifts influence female egg production in the scorpionfly Panorpa cognata
}

\author{
L E IF E N G Q V I S T Department of Evolutionary Biology and Ecology, University of Bonn, Germany
}

\begin{abstract}
Before copulation, male Panorpa cognata scorpionflies offer females a salivary secretion, which is consumed by the female during copulation. It has previously been demonstrated that this nuptial food gift functions as mating effort by increasing male attractiveness and by increasing ejaculate transfer during copulation.

2. In this study, the effect of saliva consumption on female reproductive output was investigated, and thus the possibility that nuptial food gifts also serve as paternal investment. The experimental design enabled the effect of nuptial gift consumption to be disentangled from other possible effects of multiple mating or increased copula duration.

3. The results showed that saliva consumption increases female egg production by on average $8 \%$ (4.5 eggs) per consumed salivary mass, whereas mean egg weight was not influenced.

4. These results have important implications for the evolution and maintenance of both male nuptial gifts and female polyandry in this and other species.
\end{abstract}

Key words. Female fecundity, mating effort, Mecoptera, nuptial food gifts, paternal investment, sexual selection.

\section{Introduction}

The traditional view that female fitness should be maximized with only one or a few matings (Bateman, 1948) is often challenged by the observation of female multiple matings in many species (e.g. Parker, 1970; Ridley, 1990; Hunter et al., 1993; Eberhard, 1996). The adaptive significance of female polyandry has therefore been a recurrent subject of many recent studies in evolutionary biology (reviews in Ridley, 1988; Arnqvist \& Nilsson, 2000; Jennions \& Petrie, 2000; Zeh \& Zeh, 2003; Simmons, 2005). However, the maintenance of female polyandry is easily understood if females are limited by the availability of viable sperm supply or obtain material benefits from males at mating (Arnqvist \& Nilsson, 2000). In species with male nuptial gifts, female material benefits from male investment is therefore often the default explanation for polyandry (see, for example, Arnqvist \& Nilsson, 2000; Jennions \& Petrie, 2000).

On the other hand, male nuptial gifts may also function solely as mating effort (Wickler, 1985; Simmons \& Parker, 1989) and there are many studies that, despite relatively high statistical power, have failed to demonstrate any positive influence of the

\footnotetext{
Correspondence: Leif Engqvist, Institut für Evolutionsbiologie und Ökologie, Rheinische Friedrich-Wilhelms-Universität Bonn, An der Immenburg 1, D-53121 Bonn, Germany. E-mail: lengqvist@evolution. uni-bonn.de
}

number or size of nuptial gifts on the female fitness traits studied (e.g. Gwynne et al., 1984; Jones et al., 1986; Svärd \& Wiklund, 1988; Wedell \& Arak, 1989; Will \& Sakaluk, 1994; Ward \& Landolt, 1995; Vahed \& Gilbert, 1997; Cook, 1999; Maxwell, 2000; Ryne et al., 2001; Vahed, 2003; see also Torres-Vila et al., 2004).

Furthermore, in many cases it is difficult to manipulate female nuptial gift reception without changes in female mating frequency. This is a problem, as female direct benefits from multiple mating per se have been shown to be considerable (Ridley, 1988; Arnqvist \& Nilsson, 2000). For example, sperm replenishment may influence female reproductive output (e.g. Baker et al., 2001; Drnevich et al., 2001) and substances in the ejaculate may induce egg production (see, for example, Chapman et al., 1998) and stimulate oviposition (Leopold, 1976; Eberhard, 1996). Therefore, in many studies demonstrating direct benefits from nuptial gifts (Hayashi, 1998; Ryne et al., 2001; Fedorka \& Mousseau, 2002; Rooney \& Lewis, 2002; for earlier papers see Vahed, 1998) it is difficult to disentangle benefits from nuptial feeding from other effects resulting from multiple mating or increased sperm transfer (but see Gwynne, 1984; Steele, 1986; Simmons, 1988, 1990; Brown, 1997; Reinhold, 1999). In this study, using the scorpionfly Panorpa cognata (Ramb.) (Insecta: Mecoptera), these problems are avoided, as the number of food gifts received is the only factor manipulated, and egg production is measured instead of oviposition rates. 
Male provision of food gifts during courtship and copulation is widespread in insects (Thornhill, 1976; Vahed, 1998). Nuptial food gifts may take the form of prey items, parts or the whole of the male body, as well as glandular secretions (reviewed by Vahed, 1998). Finally the spermatophore itself can be nutritious and 'digested' within the female genital tract (e.g. Boggs \& Gilbert, 1979). Except for a few species of Diptera (e.g. Steele, 1986), salivary secretions as nuptial gifts seem to be restricted to the Mecopteran genus Panorpa (Thornhill, 1976; Vahed, 1998). But within Panorpa, male production of salivary secretions on which females feed during copulation is widespread and possibly universal (Thornhill, 1976). Saliva is produced in the labial gland and there is a striking sexual dimorphism in the size of this gland; upon dissection of well-fed males, it is definitely the most prominent interior organ (L. Engqvist, pers. obs.).

Previous studies on $P$. cognata have shown that during their lifetime, females copulate several times but refuse to mate with males without receiving a nuptial gift (Engqvist \& Sauer, $2003 b)$. Furthermore, by increasing the size of the secretion males achieve longer copulations (Engqvist \& Sauer, 2001) and transfer more sperm (Engqvist \& Sauer, 2003a). Hence, the salivary secretions serve twofold as mating effort (Simmons \& Parker, 1989). The aim of this study was to investigate the influence of female consumption of salivary masses on female egg production and egg weight; thus, do females obtain material benefits at copulation?

\section{Methods}

$\mathrm{F}_{1}$ offspring from field-caught adults (near Freiburg i. Br., in south-western Germany) that were bred using standard breeding protocols were used (see Sauer, 1977; Thornhill \& Sauer, 1992). After adult emergence, experimental females were held individually in small $(8 \times 3.5 \mathrm{~cm})$ plastic tubes and supplied with water ad libitum. Furthermore, they were held on a restricted diet, since it has been suggested that nuptial feeding may be of nutritional value to females only when females are under food stress (e.g. Gwynne et al., 1984; Wedell \& Arak, 1989). Hence, at emergence they were given a one-segment piece of a mealworm (Tenebrio molitor) and thereafter on days 6, 12, 20, 26, and 32.

All females used in the experiment were allowed to mate once. Matings were performed using plastic boxes $(10 \times 10 \times 7 \mathrm{~cm})$ containing moist paper tissues. In addition, since $P$. cognata preferably mate on the underside of leaves, nettle plants (Urtica dioica) were cut at each inter-node, and all mating boxes were provided with a minute vessel containing such a miniature nettle plant and water. One female and one male were paired randomly and put in each box. The males that were used in these matings were well fed (a one-segment piece of a mealworm every third day) and between 14 and 25 days old. Furthermore, only males that were obviously emitting pheromones and thus 'calling' for females were used (see also Thornhill, 1979; Engqvist \& Sauer, 2003b). Before every mating trial, females were weighed to the nearest $0.1 \mathrm{mg}$. Females that copulated for less than $2 \mathrm{~h}$ or did not feed on the salivary secretion were not considered any further. Females were between 14 and 19 days old on the day of copulation. Subsequent to the matings, females that copulated were put individually in 'oviposition boxes' where they were kept for the remainder of the experiment. These boxes were identical to the ones used for the mating trials but contained a peat-filled Petri dish for egg laying.

In many Panorpa species, males produce several additional secretions during the course of the mating, but in $P$. cognata males secrete only one, though large, salivary mass before the onset of copulation (Engqvist \& Sauer, 2003b). The wet weight of the salivary mass amounts to $1-2.5 \mathrm{mg}$, which correspond to approximately $2-6 \%$ of the total male weight (L. Engqvist \& K. P. Sauer, unpublished data). As females readily consume salivary secretions without copulating, it is easy to collect and additionally feed females a relatively large amount of saliva without the confounding effect of an increased number of matings or increased copulation duration.

Females were assigned randomly to one of two treatments. Females in the experimental treatment were supplied with two additional salivary masses to feed on. These salivary secretions were collected from pseudomating trials of pairs not used in the main experiment. These pseudomatings were performed as previously described, but subsequent to the male production of a salivary mass, pairs were interrupted and captured. An open plastic cylinder containing an experimental female was placed upside down over the salivary secretion enabling the female to feed but not to escape. Females were given the first salivary mass $2-5$ days and the second 7-10 days after the copulation. One female from the experimental treatment had to be discarded, since it was unable to locate and feed on the second salivary mass. Control females were not provided with any additional salivary secretions but apart from that were treated the same as females in the experimental treatment.

All females were killed under $\mathrm{CO}_{2}$ anaesthesia on the 35th day, i.e. at least 7 days after the experimental females had received their second additional salivary secretion. Females were subsequently dissected in WeISE buffer (6.4 $\mathrm{mM} \mathrm{Na}_{2} \mathrm{HPO}_{4}$, $3.6 \mathrm{mM} \mathrm{KH}_{2} \mathrm{PO}_{4}$ ) and the number of remaining eggs in the ovaries was counted. As a measure of egg production, the total number of eggs produced until dissection was used, i.e. the number of remaining eggs added to the number of eggs already laid. Additionally, differences in egg weight between treatments was analysed; 10 eggs from each female were picked at random and their total weight were estimated to the nearest $0.001 \mathrm{mg}$.

\section{Statistical analysis}

Female weight is known to have a large influence on female fecundity in this species (Engqvist \& Sauer, 2003a, b). Therefore, female weight on the day of copulation was used as a covariate in an ANCOVA model. Unfortunately, due to logistic constraints and the fact that females only mate with a probability of approximately $50 \%$ when given a chance, not all females were of equal age at the day of copulation; instead it varied from 14 to 19 days. Therefore, the time interval between the last mealworm meal and copulation varied from 2 to 7 days. A food meal is typically accompanied by a drastic weight increase followed by a continuous weight loss until the next mealworm meal. Consequently, a significant part of the variation in female copulation 
weight was due to variation in the time interval between feeding and copulation $\left(r=-0.49, F_{1,57}=18.1, P<0.001\right)$. In the total data set, female copulation weight therefore correlated positively with female egg production $\left(r=0.25, F_{1,57}=3.94, P=\right.$ $0.05)$, but by including the time interval between feeding and copulation as a variable in the regression, the relationship between copulation weight and egg production became more robust ( $r=0.46, F_{1,57}=11.1, P=0.002$ ) and the proportion of explained variance in egg production increased from 0.065 to $0.2\left(F_{2,56}=6.79, P=0.002\right)$. For that reason, the time interval between the last mealworm meal and copulation was included as a covariate in the ANCOVA model. These variables were also entered as covariates in the analysis of egg weight and in the different analyses of weight differences due to salivary mass consumption. The residual variance from these models neither violated the assumption of normality (Lilliefors test: all $P>0.2$ ), nor the assumption of homoscedasticity (Levene test: all $F_{1,56} \leq$ 2.62 , all $P>0.1$ ). Furthermore, the slopes of the covariates did not differ significantly between groups (copulation weight $\times$ treatment: all $F_{1.53} \leq 2.74$, all $P>0.1$; time interval $\times$ treatment: all $F_{1,53} \leq 1.90$, all $P>0.1$ ).

\section{Results}

Altogether, 58 females were used, 29 females from the experimental treatment and 29 from the control treatment. On average, females produced $56.71 \pm 16.1$ (SD) eggs with an average weight of $0.191 \pm 0.033$ (SD) mg. The AnCOva model revealed that females in the experimental treatment produced significantly more eggs than females in the control treatment (ANCOVA: treatment: $F_{1,54}=5.51, P=0.02$; covariates: female copulation weight $F_{1,54}=13.3, P=0.001$; time interval $F_{1,54}=13.1$, $P=0.001$, Fig. 1). The mean difference in egg production between treatments amounted to $8.96 \pm 3.81$ (SE) eggs. There was, however, no difference in egg weight between treatments (mean \pm SE difference: $-0.0041 \pm 0.0091 \mathrm{mg}$; ANCOVA: treatment: $F_{154}=0.20, P=0.66$; covariates: female copulation weight $F_{1,54}=0.034, P=0.86$; time interval $F_{1,54}=1.21, P=$ $0.28)$.

The increase in egg production for females in the experimental treatment may not necessarily be an effect of nutritional resource benefits. Instead, for instance substances in the salivary mass may affect resource allocation and increase the investment in reproductive tissue at the expense of soma investment (e.g. Wedell \& Karlsson 2003). Therefore both soma weight at the end of the experiment and total weight gain between females from both treatments were compared. A measure of female soma weight was obtained indirectly from female dissection weight and the number of dissected eggs (dissection weight number of dissected eggs $\times$ average egg weight). The soma weight of females that were allowed to feed on additional salivary masses was slightly larger than the soma weight of control females (mean \pm SE difference: $1.56 \pm 1.05$ eggs) but this difference was not statistically significant (ANCOVA: treatment: $F_{1,54}=2.15, P=0.15$; covariates: female copulation weight $F_{1,54}=11.7, P=0.001$; time interval $F_{1,54}=6.71, P=0.012$ ). Since some, but not all, females oviposited before dissection, it

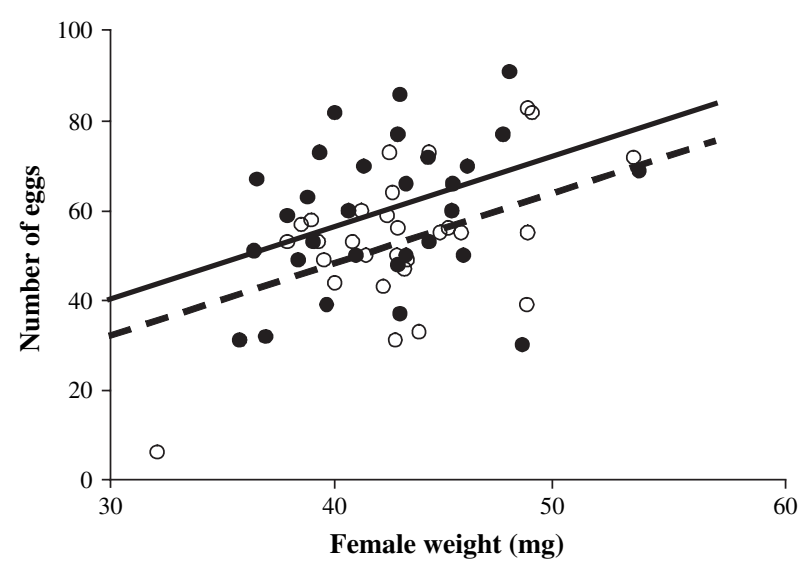

Fig.1. The effect of the treatment, feeding supplement of two salivary secretions, on the number of eggs produced when controlling for female weight $(\bullet$ and - , salivary mass treatment; $\bigcirc$ and --- , control treatment). On the $x$-axis is the copulation weight adjusted for variance due to differences in the time interval between copulation and the last mealworm meal (i.e. mean female weight + residual weight from the regression on time interval between the last mealworm meal and copulation). Residual weight was only used to illustrate the treatment effect in a two-dimensional diagram. In the analysis, both variables were used as covariates.

was not possible to straightforwardly compare net weight gain between female treatments. Instead, the weight gain of those females that laid eggs during the trial $(n=21)$ had to be adjusted with the weight loss from oviposition (number of laid eggs $\times$ average egg weight). Females in the experimental treatment gained significantly more weight during the experimental phase of the study (mean \pm SE difference: $3.46 \pm 1.21 \mathrm{mg}$; ANCOVA: treatment: $F_{1,54}=8.14, P=0.006$; covariates: female copulation weight $F_{1,54}=3.20, P=0.079$; time interval $F_{1,54}=21.7$, $P<0.001)$.

\section{Discussion}

In this study it has been demonstrated that in P. cognata, nuptial feeding of salivary secretions during copulation increases female egg production significantly, but it has no detectable effect on egg weight, at least under these experimental conditions. This experimental design makes it possible to exclude the potential effects of different mating rates and different sperm supply between treatments. Male saliva might potentially contain substances that might induce an increase in female oviposition, similar to many accessory ejaculate substances (Eberhard, 1996; Chapman et al., 1998). As egg production was measured, this cannot have influenced the results, although the existence of such substances cannot be excluded. One possibility remains: male saliva might potentially contain substances that manipulate females to increase investment in reproductive tissue at the expense of soma investment, as has been shown for male donations in, for instance, butterflies (Stjernholm \& Karlsson, 2000; Wedell \& Karlsson, 2003). In contrast to the predictions from this hypothesis, however, the increase in reproductive output was not accompanied by a decrease in soma weight. Instead, as 
expected by a nutritional resource benefit from nuptial gift consumption, experimental females experienced a higher net weight increase.

How significant are female direct benefits of polyandry in this species?

In many, if not the majority of insect species, females mate with multiple males (Ridley, 1988, 1990), although in most cases the adaptive significance of multiple mating is not as apparent for female as for males (Bateman, 1948). Nevertheless, in a recent meta-analysis of fitness consequences from polyandry in insects, Arnqvist and Nilsson (2000) demonstrated that the average direct female fitness gain from multiple mating is substantial. Furthermore, in species in which females receive nuptial gifts, the fitness gain in terms of lifetime reproductive success was as high as $35-85 \%$ (Arnqvist \& Nilsson, 2000). In light of these data, the maintenance of polyandry, especially in species with nuptial gifts, seem easily understood. However, in most studies that have addressed the question of female benefits of polyandry in species with nuptial gifts, it has been difficult to disentangle direct nutritional benefits from direct benefits from multiple mating and sperm replenishment per se. The relatively few equivalent studies in other species with nuptial food gifts have revealed both substantial effects (Gwynne, 1984; Steele, 1986; Simmons, 1988, 1990; Brown, 1997; Reinhold, 1999) as well as no apparent benefits from nuptial feeding (Gwynne et al., 1984; Jones et al., 1986; Wedell \& Arak, 1989; Will \& Sakaluk, 1994; Vahed \& Gilbert, 1997; Maxwell, 2000; Vahed, 2003). Data from Mecoptera, which includes a large number of species with nuptial food gifts, have thus far been lacking. However, recent data from $P$. vulgaris show that females respond with an increased reproductive output following longer copulations involving a larger amount of saliva (Engels \& Sauer, 2006).

The effect of saliva consumption on egg production in $P$. cognata is relatively small compared with other factors, such as, for instance, female body weight. Nevertheless, for individual females, the fitness increase due to salivary mass consumption at mating may be substantial. In this study, the estimate of female nutritional benefits from salivary mass consumption, and thus additional matings, is in the magnitude of four or five eggs, or roughly $8 \%$. Mean estimates of the lifetime fitness increase of polyandrous females due to salivary mass consumption, which take both the lifetime number of female matings (see Engqvist \& Sauer, 2003b) and the relative fitness increase per mating into account, would therefore be in the magnitude of slightly more than $30 \%$ for females subjected to a highly restricted diet as in the present study and approximately $20 \%$ for females in populations with ample food abundance. These estimates are thus slightly lower than the average direct benefit of multiple mating in insect species with nuptial gifts (Arnqvist \& Nilsson, 2000). However, these estimates only entail the direct benefits of polyandry with respect to salivary mass consumption. Females may also receive other direct benefits from multiple mating, for instance fertility assurance, not considered in this study. Moreover, in a recent study, it was demonstrated that $P$. cognata females benefit by mating with different males, which suggests genetic benefits of polyandry (Engqvist, 2006). Thus, both direct nutritional and indirect genetic benefits seem important factors affecting the selection pressure on female multiple mating in this scorpionfly.

\section{Nuptial gifts as paternal investment?}

Irrespective of the adaptive significance of female polyandry resulting from large gift donation, the evolution and maintenance of nuptial gifts must be explained from the perspective of male function. Principally, nuptial gifts may have two non-mutually exclusive functions: they may increase male attractiveness, and thus mating opportunities, and/or increase the proportion of fertilised eggs from a given female, and therefore represent mating effort (Simmons \& Parker, 1989). Second, they can function as paternal investment (Thornhill, 1976).

To demonstrate that the nuptial food gift functions as paternal investment requires that the gift increases offspring number or fitness and that this increase affects the gift-producing male's own offspring (Parker, 1979; Wickler, 1985). The increase in female egg production due to salivary mass consumption suggests that the salivary secretion donated by males prior to copulation at least potentially functions as paternal investment. Whether the male's own offspring are affected will depend upon the time it takes to incorporate male nutrients into mature eggs, the total number of males the gift-receiving female will mate with until egg laying, and the mechanism of sperm competition (Wickler, 1985; Simmons \& Parker, 1989; Vahed, 1998).

Paternity studies have shown that the mode of sperm competition in this species conform largely to a fair raffle model (Engqvist et al., in press), as has also been demonstrated for the related species Panorpa vulgaris (Sauer et al., 1998, 1999). In semi-natural enclosure populations, paternity is on average shared among four males in the first egg batch (L. Engqvist \& K. P. Sauer, unpublished data). As in the present study the average increase in female egg production due to male investment is estimated to be 4.5 eggs per mating (95\% CI: $0.67-8.29$ eggs), the estimated mean benefit for males of nuptial food gift, in the context of paternal investment, is barely one egg per salivary mass (95\% CI: $0.17-2.1$ eggs). In light of the relatively small influence on egg production in relation to the extent of female polyandry, it seems reasonable to conclude that the current selection pressures on male salivary secretions in the function of paternal investment are at most marginal. The selection pressures on the function mating effort appear more intense, as male nuptial gift offering is necessary to achieve matings (Engqvist \& Sauer, 2003b) and the size of the salivary secretion influence both copulation duration and sperm transfer (Engqvist \& Sauer, 2001, 2003a) and female remating (Engqvist, 2007), important traits in a mating system characterised by female multiple mating and intense sperm competition. Therefore, it is presumably more appropriate to regard the effect of nuptial gift consumption on female reproductive output as an incidental side-effect of its evolved function, namely a device for acquiring matings and increasing male fertilisation success. Quinn and Sakaluk (1986) argued that such incidental effects have often arisen 
from the provision of nuptial food gifts that function primarily as mating effort.

To conclude, this study has shown that nuptial food gifts influence female egg production in the scorpionfly $P$. cognata. The salivary secretions may thus potentially function as paternal investment. However, considering the degree of female polyandry, the benefit for males of an increased egg production is likely to be small. Nonetheless, the lifetime benefit for polyandrous females due to saliva consumption may be substantial, and can thus help explain the evolution and maintenance of polyandry in this scorpionfly.

\section{Acknowledgements}

Alice Kasprzik assisted during substantial parts of the experiment. Klaus Reinhold gave statistical advice. Jutta Schneider and two anonymous referees provided valuable criticism on a previous version of this manuscript. This work was supported by the Deutsche Forschungsgemeinschaft [En 469/1-1].

\section{References}

Arnqvist, G. \& Nilsson, T. (2000) The evolution of polyandry: multiple mating and female fitness in insects. Animal Behaviour, 60, $145-164$.

Baker, R.H., Ashwell, R.I.S., Richards, T.A., Fowler, K., Chapman, T. \& Pomiankowski, A. (2001) Effects of multiple mating and male eye span on female reproductive output in the stalk-eyed fly, Cyrtodiopsis dalmanni. Behavioral Ecology, 12, 732-739.

Bateman, A.J. (1948) Intra-sexual selection in Drosophila. Heredity, 2, 349-368.

Boggs, C.L. \& Gilbert, L.E. (1979) Male contribution to egg production in butterflies: evidence for transfer of nutrients at mating. Science, 206, 83-84.

Brown, W.D. (1997) Courtship feeding in tree crickets increases insemination and female reproductive life span. Animal Behaviour, 54, 1369-1382.

Chapman, T. Miyatake, T. Smith, H.K. \& Partridge, L. (1998) Interactions of mating, egg production and death rates in females of the Mediterranean fruit fly, Ceratitis capitata. Proceedings of the Royal Society of London, Series B, 265, 1879-1894.

Cook, P.A. (1999) Sperm numbers and female fertility in the moth Plodia interpunctella (Hubner) (Lepidoptera; Pyralidae). Journal of Insect Behavior, 12, 767-779.

Drnevich, J.M., Papke, R.S., Rauser, C.L. \& Rutowski, R.L. (2001) Material benefits from multiple mating in female mealworm beetles (Tenebrio molitor L.). Journal of Insect Behavior, 14, 215-230.

Eberhard, W.G. (1996) Female Control: Sexual Selection by Cryptic Female Choice. Princeton University Press, Princeton, New Jersey.

Engels, S. \& Sauer, K.P. (2006) Love for sale and its fitness benefits: nuptial gifts in the scorpionfly Panorpa vulgaris represent paternal investment. Behaviour.

Engqvist, L., Dekomien, G., Lippmann, T., Epplen, J.T. \& Sauer, K.P. (in press) Sperm transfer and paternity in the scorpionfly Panorpa Cognata: large variance in traits favoured by post-copulatory episodes of sexual selection. Evolutionary Ecology, doi:10.1007/s10682-006-9152-6.

Engqvist, L. (2007) Nuptial gift consumption influences female remating in a scorpionfly: male or female control of mating rate? Evolutionary Ecology, 21, 49-61.
Engqvist, L. (2006) Females benefit from mating with different males in the scorpionfly Panorpa cognata. Behavioral Ecology, 17, 435-440.

Engqvist, L. \& Sauer, K.P. (2001) Strategic male mating effort and cryptic male choice in a scorpionfly. Proceedings of the Royal Society of London, Series B, 268, 729-735.

Engqvist, L. \& Sauer, K.P. (2003a) Determinants of sperm transfer in the scorpionfly Panorpa cognata: male variation, female condition and copulation duration. Journal of Evolutionary Biology, 16, 1196-1204.

Engqvist, L. \& Sauer, K.P. (2003b) Influence of nutrition on courtship and mating in the scorpionfly Panorpa cognata. Ethology, 109, 911-928.

Fedorka, K.M. \& Mousseau, T.A. (2002) Material and genetic benefits of female multiple mating and polyandry. Animal Behaviour, 64, 361-367.

Gwynne, D.T. (1984) Courtship feeding increases female reproductive success in bushcrickets. Nature, 307, 361-363.

Gwynne, D.T., Bowen, B.J. \& Codd, C.G. (1984) The function of the katydid spermatophore and its role in fecundity and insemination (Ortoptera: Tettigonidae). Australian Journal of Zoology, 32, $15-22$.

Hayashi, F. (1998) Multiple mating and lifetime reproductive output in female dobsonflies that receive nuptial gifts. Ecological Research, 13, 283-289.

Hunter, F.M., Petrie, M., Otronen, M., Birkhead, T. \& Moller, A.P. (1993) Why do females copulate repeatedly with one male. Trends in Ecology and Evolution, 8, 21-26.

Jennions, M.D. \& Petrie, M. (2000) Why do females mate multiply? A review of the genetic benefits. Biological Reviews, 75, 21-64.

Jones, K.N., Odendaal, F.J. \& Ehrlich, P.R. (1986) Evidence against spermatophore as paternal investment in Checkerspot butterflies (Euphydryas: Nymphalidae). American Midland Naturalist, 116, 1-6.

Leopold, R.A. (1976) The role of male accessory glands in insect reproduction. Annual Review of Entomology, 21, 199-221.

Maxwell, M.R. (2000) Does a single meal affect female reproductive output in the sexually cannibalistic praying mantid Iris oratoria? Ecological Entomology, 25, 54-62.

Parker, G.A. (1970) Sperm competition and its evolutionary consequences in the insects. Biological Reviews, 45, 525-567.

Parker, G.A. (1979) Sexual selection and sexual conflict. Sperm Competition and the Evolution of Animal Mating Systems (ed. by M. S. Blum and N. A. Blum), pp. 1-60. Academic Press, New York.

Quinn, J.S. \& Sakaluk, S.K. (1986) Prezygotic male reproductive effort in insects: why do males provide more than sperm? Florida Entomologist, 69, 84-94.

Reinhold, K. (1999) Paternal investment in Poecilimon veluchianus bushcrickets: beneficial effects of nuptial feeding on offspring viability. Behavioral Ecology and Sociobiology, 45, 293-299.

Ridley, M. (1988) Mating frequency and fecundity in insects. Biological Reviews, 63, 509-549.

Ridley, M. (1990) The control and frequency of mating in insects. Functional Ecology, 4, 75-84.

Rooney, J. \& Lewis, S.M. (2002) Fitness advantage from nuptial gifts in female fireflies. Ecological Entomology, 27, 373-377.

Ryne, C., Zhu, J.W., Van Dongen, S. \& Löfstedt, C. (2001) Spermatophore size and multiple mating: effects on reproductive success and post-mating behaviour in the Indian meal moth. Behaviour, 138, 947-963.

Sauer, K.P. (1977) The adaptive significance of genetic variability of photoperiodic response in Panorpa vulgaris. Zoologische Jahrbücher: Abteilung für Systematik, Ökologie und Geographie der Tiere, 104, 489-538. 
Sauer, K.P., Epplen, C., Over, I., Lubjuhn, T., Schmidt, A., Gerken, T. et al. (1999) Molecular genetic analysis of remating frequencies and sperm competition in the scorpionfly Panorpa vulgaris (Imhoff and Labram). Behaviour, 136, 1107-1121.

Sauer, K.P., Lubjuhn, T., Sindern, J., Kullmann, H., Kurtz, J. \& Epplen, C. \& Epplen, J.T. (1998) Mating system and sexual selection in the scorpionfly Panorpa vulgaris (Mecoptera: Panorpidae). Naturwissenschaften, 85, 219-228.

Simmons, L.W. (1988) The contribution of multiple mating and spermatophore consumption to the lifetime reproductive success of female field crickets (Gryllus bimaculatus). Ecological Entomology, 13, 57-69.

Simmons, L.W. (1990) Nuptial feeding in tettigoniids: male cost and the rates of fecundity increase. Behavioral Ecology and Sociobiology, 27, 43-47.

Simmons, L.W. (2005) The evolution of polyandry: sperm competition, sperm selection, and offspring viability. Annual Review of Ecology, Evolution and Systematics, 36, 125-146.

Simmons, L.W. \& Parker, G.A. (1989) Nuptial feeding in insects: mating effort versus paternal investment. Ethology, 81, 332-343.

Steele, R.H. (1986) Courtship feeding in Drosophila subobscura. I. The nutritional significance of courtship feeding. Animal Behaviour, 34, 1087-1098.

Stjernholm, F. \& Karlsson, B. (2000) Nuptial gifts and the use of body resources for reproduction in the green-veined white butterfly Pieris napi. Proceedings of the Royal Society of London, Series B, 267, 807-811.

Svärd, L. \& Wiklund, C. (1988) Fecundity, egg weight and longevity in relation to multiple matings in females of the monarch butterfly. Behavioral Ecology and Sociobiology, 23, 39-43.

Thornhill, R. (1976) Sexual selection and paternal investment in insects. American Naturalist, 110, 153-163.

Thornhill, R. (1979) Male pair-formation pheromones in Panorpa scorpionflies (Mecoptera: Panorpidae). Environmental Entomology, 8, 886-888.
Thornhill, R. \& Sauer, K.P. (1992) Genetic sire effects on the fighting ability of sons and daughters and mating success of sons in a scorpionfly. Animal Behaviour, 43, 255-264.

Torres-Vila, L.M. \& Rodriguez-Molina, M.C. \& Jennions, M.D. (2004) Polyandry and fecundity in the Lepidoptera: can methodological and conceptual approaches bias outcomes? Behavioral Ecology and Sociobiology, 55, 315-324.

Vahed, K. (1998) The function of nuptial feeding in insects: a review of empirical studies. Biological Reviews, 73, 43-78.

Vahed, K. (2003) Increases in egg production in multiply mated female bushcrickets Leptophyes punctatissima are not due to substances in the nuptial gift. Ecological Entomology, 28, 124-128.

Vahed, K. \& Gilbert, F.S. (1997) No effect of nuptial gift consumption on female reproductive output in the bushcricket Leptophyes laticauda Friv. Ecological Entomology, 22, 479-482.

Ward, K.E. \& Landolt, P.J. (1995) Influence of multiple matings on fecundity and longevity of female cabbage looper moths (Lepidoptera, Noctuidae). Annals of the Entomological Society of America, 88, 768-772.

Wedell, N. \& Arak, A. (1989) The wartbiter spermatophore and its effect on female reproductive output (Orthoptera: Tettigonidae, Decticus verrucivorus). Behavioral Ecology and Sociobiology, 24, 117-125.

Wedell, N. \& Karlsson, B. (2003) Paternal investment directly affects female reproductive effort in an insect. Proceedings of the Royal Society of London, Series B, 270, 2065-71.

Wickler, W. (1985) Stepfathers in insects and their pseudo-parental investment. Zeitschrift für Tierpsychologie, 69, 72-78.

Will, M.W. \& Sakaluk, S.K. (1994) Courtship feeding in decorated crickets - is the spermatophylax a sham? Animal Behaviour, 48 1309-1315.

Zeh, J.A. \& Zeh, D.W. (2003) Toward a new sexual selection paradigm: polyandry, conflict and incompatibility. Ethology, 109, 929-950.

Accepted 20 July 2006

First published online 13 April 2007 